\section{COMPUTATIONAL STUDY OF FLUIDIC THRUST VECTORING USING SEPARATION CONTROL IN A NOZZLE}

Karen A. Deere*, Bobby L. Berrier ${ }^{\dagger}$, Jeffrey D. Flamm Aerodynamics, Aerothermodynamics, and Acoustics Competency NASA Langley Research Center, Hampton, Virginia Stuart K. Johnson

Aerospace Systems Concepts \& Analysis Competency NASA Langley Research Center, Hampton, Virginia

\section{ABSTRACT}

A computational investigation of a twodimensional nozzle was completed to assess the use of fluidic injection to manipulate flow separation and cause thrust vectoring of the primary jet thrust. The nozzle was designed with a recessed cavity to enhance the throat shifting method of fluidic thrust vectoring. The structured-grid, computational fluid dynamics code PAB3D was used to guide the design and analyze over 60 configurations. Nozzle design variables included cavity convergence angle, cavity length, fluidic injection angle, upstream minimum height, aft deck angle, and aft deck shape. All simulations were computed with a static freestream Mach number of 0.05 , a nozzle pressure ratio of 3.858 , and a fluidic injection flow rate equal to 6 percent of the primary flow rate. Results indicate that the recessed cavity enhances the throat shifting method of fluidic thrust vectoring and allows for greater thrust-vector angles without compromising thrust efficiency.

\section{INTRODUCTION}

Fluidic injection for thrust-vector angle control and throat area control in exhaust nozzles has been studied for over 10 years. Unlike mechanical thrustvectoring nozzles that use actuated hardware to vector the primary jet thrust, fluidic thrust-vectoring nozzles use a secondary air stream to manipulate the primary jet flow. Therefore, fixed geometry, fluidic thrustvectoring nozzles could have better stealth characteristics and weigh less than their mechanical thrust vectoring counterparts.

\footnotetext{
* Research Engineer, Configuration Aerodynamics Branch (CAB), Senior Member AIAA

$\dagger$ Associate Branch Head, CAB. AIAA Fellow

${ }^{\ddagger}$ Research Engineer, CAB. Senior Member AIAA

${ }^{\S}$ Research Engineer, Advanced Aircraft Branch.

This material is declared a work of the U.S. Government and is not subject to copyright protection in the United States.
}

The three primary methods for fluidic thrust vectoring include shock vector control, throat shifting, and counterflow (refs. 1-10). Fluidic shock vector control methods manipulate the supersonic flow in the divergent section of the nozzle, as do mechanical schemes that utilize post-exit flaps or vanes, aft-hoods, or deflected divergent flaps (refs. 1113). This method (fluidic injection downstream of nozzle throat) offers substantial thrust-vector angles, but often at the expense of thrust ratio. Thrust vectoring efficiencies up to $3.3 \% \%$-injection and thrust ratios in the range of 0.86 to 0.94 are typical for shock vector control methods (refs. 1-4).

Higher thrust ratios are generally obtained with throat shifting methods (fluidic injection at the nozzle throat). Fluidic throat shifting methods act to efficiently turn the flow at subsonic conditions by manipulating the sonic plane at or near the throat of the nozzle, much the same as the mechanical predecessors in references 14-16. Although throat shifting technology is currently improving, thrustvector angles reported to date would generally be sufficient for mild maneuver adjustments only. Thrust ratios in the range of 0.94 to 0.98 and vectoring efficiencies up of $2 \%$-injection are typical for traditional throat shifting methods (refs. 6, 17-18).

Unlike shock vector control and throat shifting methods that utilized fluidic injection, the counterflow method uses secondary suction, applied asymmetrically between the trailing edge of a primary nozzle and an aft shrouded collar (or divergent flap). The vacuum creates reversed flow along the collar. The shear layers mix and entrain flow, but the collar inhibits mass entrainment, which causes the flow to accelerate, and the pressure to drop. The asymmetric pressure loading causes vectored jet thrust. References 5 and 6 contain more details on the counterflow method. This method (suction in a secondary duct) offers large thrust-vector angles with little secondary flow requirements, but issues such as suction supply source, hysteresis effects, and airframe integration need to be addressed. Thrust ratios in the range of 0.92 to 0.97 are associated with the counterflow method (refs. 7-8).

The fluidic thrust vectoring technique investigated in the present study maintains high thrust efficiencies associated with the throat shifting method while increasing the thrust-vectoring efficiency, by maximizing pressure differentials of the separated and attached flows in a recessed cavity. A sketch of the recessed cavity nozzle concept is shown in figure 1 . The recessed cavity section was located between upstream and downstream minimum areas 
and fluidic injection was introduced at the upstream minimum area. Nozzle design variables, shown in figure 2 , included cavity convergence angle, cavity length, fluidic injection angle, upstream minimum height, aft deck angle, and aft deck shape. The structured-grid, computational fluid dynamics code PAB3D was used to guide the design and analyze over 60 configurations. All simulations were computed with a static freestream Mach number of 0.05 , a nozzle pressure ratio of 3.858 , and a fluidic injection flow rate equal to 6 percent of the primary flow rate. A symmetric nozzle with the separation-enhanced, throat shifting method reached system thrust ratios in the range of 0.94 to 0.97 and vectoring efficiencies up to $2.15 \%$-injection. Vectoring efficiencies up to $3 \%$ injection were achieved with an aft deck configuration at certain conditions.

\section{NOMENCLATURE}

$\mathrm{C}_{\mathrm{f}, \mathrm{g}, \mathrm{sys}} \quad$ system thrust ratio, $\mathrm{F}_{\mathrm{r}} /\left(\mathrm{F}_{\mathrm{i}, \mathrm{p}}+\mathrm{F}_{\mathrm{i}, \mathrm{s}}\right)$

d depth of recessed cavity

ETA extended tangent arc

ETTA extended translated tangent arc

$\mathrm{F}_{\mathrm{A}} \quad$ axial force

$\mathrm{F}_{\mathrm{N}} \quad$ normal force

$\mathrm{F}_{\mathrm{r}} \quad$ resultant force

$\mathrm{F}_{\mathrm{i}, \mathrm{p}} \quad$ ideal isentropic thrust of primary flow

$\mathrm{F}_{\mathrm{i}, \mathrm{s}} \quad$ ideal isentropic thrust of fluidic injection flow

$\mathrm{h}_{1} \quad$ height at upstream minimum area

$\mathrm{h}_{2} \quad$ height at downstream minimum area, $1.15 \mathrm{in}$.

$\mathrm{k} \quad$ turbulent kinetic energy

L cavity length

LWI lower-wall injection

M freestream Mach number

NPR nozzle pressure ratio, $\mathrm{p}_{\mathrm{t}, \mathrm{j}} / \mathrm{p}$

$\mathrm{NPR}_{\mathrm{D}}$ design nozzle pressure ratio

$\mathrm{p} \quad$ surface static pressure

$\mathrm{p}_{\mathrm{t}, \mathrm{j}} \quad$ primary flow total pressure

$\mathrm{p}$ freestream static pressure

RTA rotated tangent arc

TA tangent arc

TTA translated tangent arc

UWI upper-wall injection

$\mathrm{w}_{\mathrm{p}} \quad$ actual primary weight flow

$\mathrm{w}_{\mathrm{s}} \quad$ actual fluidic injection weight flow

$\mathrm{x}$ distance downstream of upstream minimum

$\mathrm{x}_{1} \quad$ length of cavity divergence

$\mathrm{x}_{2} \quad$ length of cavity convergence

$\mathrm{y}^{+} \quad$ nondimensional first cell height

$\mathrm{z} \quad$ distance above nozzle centerline

․ aft deck angle

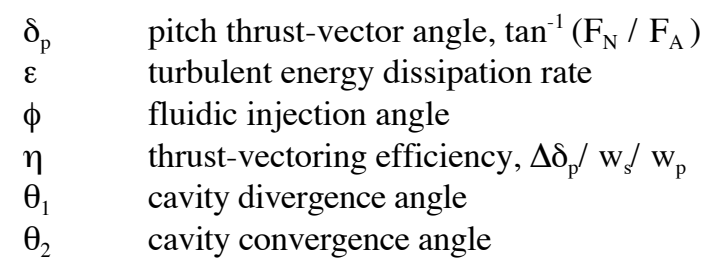

\section{COMPUTATIONAL METHOD}

\section{Governing Equations}

The computational fluid dynamics code PAB3D solves the three-dimensional, Reynolds-averaged Navier-Stokes (RANS) equations and uses one of several turbulence models for closure of the RANS equations. The governing equations are written in generalized coordinates and in conservative form. In an effort to decrease computational resources, the simplified, thin-layer Navier-Stokes equations are implemented into PAB3D. This approximation neglects derivatives in the viscous terms in the streamwise and parallel directions to the surface, since they are typically negligible in comparison to the derivatives normal to the surface.

The flow solver was written with three numerical schemes: the flux vector-splitting scheme of van Leer (ref. 21), the flux difference-splitting scheme of Roe (ref. 22), and a modified Roe scheme primarily used for space marching solutions. These schemes implement the finite volume principle to balance the fluxes across grid cells and the upwind biased scheme of van Leer or Roe to determine fluxes at the cell interfaces. Only the inviscid terms of the flux vectors are split and upwind differenced, while the diffusion terms of the Navier-Stokes equations are central differenced. Extensive details of PAB3D are found in references 19 through 23.

\section{Turbulence Modeling}

Turbulence modeling is required to predict many flow fields. The PAB3D code can perform several different turbulence simulations by utilizing either algebraic, linear 2-equation, or nonlinear 2-equation turbulence models. The 2-layer, algebraic BaldwinLomax model is accurate for simple viscous flows because the turbulent viscosity is determined by a local function. The 2-equation $\mathrm{k}-\mathrm{C}$ turbulence model, with second order closure, is used to model more complex viscous flow features.

The pair of coupled transport equations, turbulent kinetic energy (k) and turbulent energy dissipation rate ( $\square$, are written in conservative form and can be uncoupled from the Navier-Stokes equations and from 
each other to decrease computational requirements. In an effort to decrease numerical stiffness, the $\mathrm{k}$ and $\square$ equations are solved at approximately 25 percent of the Courant-Friedrichs-Levy (CFL) number for the NavierStokes equations. Further details about the turbulence models in PAB3D can be found in references 19 and 23.

Since the k- $\square$ turbulence model has a singularity at solid surfaces, either a damping function or a wall function must be implemented to adjust the turbulent energy dissipation rate $(\square)$ at solid surfaces. The grid in the boundary layer at wall surfaces must be well defined with a law-of-the-wall coordinate $\left(\mathrm{y}^{+}\right)$of 2 or less, for adequate modeling of the boundary layer flow (ref. 23). The restriction on $\mathrm{y}^{+}$may be relaxed to 50 if a wall function is implemented. However, it is customary to restrict the use of wall functions to attached flow only, which typically only occurs in nozzle flows at $N P R \geq N P R_{D}$. Exhaust nozzles utilizing fluidic injection generally experience regions of separated flow. Likewise, all nozzles at overexpanded conditions $\left(\mathrm{NPR}<\mathrm{NPR}_{\mathrm{D}}\right)$ contain regions of flow separation.

\section{Performance Calculation}

Nozzle performance characteristics were computed with the PAB3D post processor code, POST. The POST software package is documented at the website http://eagle.com/post/.

\section{Boundary Conditions}

The PAB3D code has many options for defining the conditions of the inflow, outflow, freestream, wall, and centerline boundaries. For this study, Riemann invariants along the characteristics were implemented along the lateral and in-flow freestream boundaries. A first order extrapolation outflow condition was used at the downstream far field boundary. The primary nozzle flow and the fluidic injection flow were specified with a fixed total-temperature and total-pressure boundary condition. A no-slip, adiabatic wall boundary condition was implemented on nozzle surfaces to obtain viscous solutions.

\section{Computational Solution}

The PAB3D code with linear 2-equation turbulence modeling was chosen for the current simulations because it was developed for and has been extensively used to accurately predict propulsive flows with mixing, separated flow regions, and jet shear layers (refs. 23-25). The current solutions are computed with the flux vector-splitting scheme of van Leer and the flux difference-splitting scheme of Roe. All solutions were computed with the linear $\mathrm{k}-\square$ turbulence model. A modified Jones and Launder form (ref. 26) of the damping function was implemented in the wall bounded blocks to treat the singularity at the wall and a high Reynolds number model was implemented in the freestream blocks.

\section{Nozzle Geometry}

The current nozzle geometry is intended to enhance the thrust vectoring capability of the throat shifting method by manipulating flow separation in a recessed cavity. The recessed cavity section was located between upstream and downstream minimum areas and fluidic injection was introduced at the upstream minimum area location. A sketch of the recessed cavity nozzle concept (without an aft deck) is shown in figure 1 . Over 60 simulations were computed to examine the effect of various nozzle design parameters including cavity convergence angle, cavity length, fluidic injection angle, upstream minimum height, aft deck angle, and aft deck shape (see figure 2). The fluidic injection slot width was held constant at 0.022 inches and the downstream minimum height was held constant at $\mathrm{h}_{2}=1.15$ inches for the entire study.

\section{Computational Domain}

The computational mesh was defined with 14 blocks in a two-dimensional domain. The internal nozzle was defined with 5 blocks, the fluidic injection plenum was defined with 1 block, and the freestream domain was defined with 8 blocks. The internal blocking structure representing the nozzle with a recessed cavity and a fluidic injection plenum is shown in figure 3. The injection plenum with one-to-one grid matching with the primary nozzle grid is shown in figure 4.

The far field was located 5 nozzle lengths upstream and 21 nozzle lengths downstream of the nozzle exit. The upper and lower lateral far field boundaries were located 28 nozzle lengths above and below the nozzle. The boundary layer was defined for a law-of-the-wall coordinate of $\mathrm{y}^{+}=0.5$ on the fine mesh spacing for adequate modeling of the boundary layer flow.

\section{RESULTS}

The structured-grid, computational fluid dynamics code PAB3D was used to guide the design and analyze over 60 variations of the recessed cavity nozzle. All simulations were computed with a static freestream Mach number of 0.05 , a nozzle pressure ratio of 3.858 , and a fluidic injection flow rate equal to 6 
percent of the primary flow rate. The actual percent of fluidic injection varied slightly from the nominal 6 percent. Therefore, thrust-vectoring efficiency $\square$ was used to compare results of simulations with slightly different amounts of fluidic injection. For a symmetric nozzle geometry (no aft deck), the thrust-vectoring efficiency is simply pitch thrust-vector angle normalized by the percent of fluidic injection. For configurations with an aft deck and no fluidic injection, there is an inherent pitch thrust-vector angle simply due to the asymmetric geometry. Therefore, thrustvectoring efficiency is computed from the difference in pitch thrust-vector angle between the no fluidic injection case and the fluidic injection case, normalized by percent of injected flow.

\section{Effect of Fluidic Injection and Injection Angle}

Nozzle pressure ratio distributions for the symmetric baseline nozzle are shown in figure 5. Data presented includes the no fluidic injection case, an injection case $\left(6 \%\right.$ at an angle of $\left.\square=150^{\circ}\right)$, and predictions from one-dimensional (1-D) isentropic stream-tube-area relations. The 1-D relations indicate the pressure ratios that would exist in the throat region ( $x=0-1$ in.) for isentropic inviscid flow based on the local area ratio.

The pressure ratio distribution for the no injection case is much lower and has a different slope than the 1$\mathrm{D}$ flow prediction distributions in most of the throat region, where separated and reversed flow exist. The pressures for the no injection case correlate well with 1-D flow prediction distributions after $\mathrm{x}=0.75$ in., where the flow attaches to the convergent wall in the throat region.

For the injection case, the flow remains attached to the upper wall throughout the nozzle, as indicated by the pressure ratio distribution that now matches the slopes of the1-D flow prediction distribution more closely, albeit at a lower value in the divergent throat region. The pressure ratios on the lower surface, however, are considerably low $\left(\mathrm{p} / \mathrm{p}_{\mathrm{t}, \mathrm{j}} \approx 0.2\right)$ as a result of the separated flow region produced in the recessed cavity. These pressures were much lower than expected from the average Mach numbers in the recessed cavity, which indicates that the recessed cavity allowed the separated flow to be pumped down further than expected by the primary flow. Previous throat shifting techniques produced pressure ratios of approximately $\mathrm{p} / \mathrm{p}_{\mathrm{t}, \mathrm{j}}=0.5$ to $\mathrm{p} / \mathrm{p}_{\mathrm{t}, \mathrm{j}}=0.6$ on the lower wall, which limited their effectiveness.

The performance of the symmetric baseline nozzle with no fluidic injection is listed as case 25 in Table 1. The effect of fluidic injection angle on nozzle performance is also shown in Table 1. The use of fluidic injection for thrust vectoring resulted in a penalty to the system thrust ratio of $1.3 \%$ to $1.9 \%$, depending on fluidic injection angle.

After accounting for this initial thrust ratio penalty (due to turning on the fluidic injection), the geometric variable that had the largest impact on thrust-vector angle with a minimal impact on thrust ratio was the fluidic injection angle ( $\square$ ). Thrustvectoring efficiency increased from $\square=0.84 \%$ injection to $\square=2.15^{\circ} \%$-injection with a mere $0.6 \%$ penalty in thrust ratio, as the fluidic injection angle was varied from injecting downstream at $\square=50^{\circ}$ to injecting upstream at $\square=150^{\circ}$. A diagram of fluidic injection angle in the two-dimensional, $\mathrm{x}-\mathrm{z}$ plane is shown in figure 6 . Of all the cases computed, the symmetric nozzle configuration that provided the highest thrust-vectoring efficiency $(2.15 \%$-injection) was the configuration with an injection angle of $\square=150^{\circ}$ (case 29).

\section{Effect of Upstream Minimum Height}

The effect of upstream minimum height $\left(h_{1}\right)$ on nozzle performance of cases with fluidic injection turned on is shown in Table 2. Although decreasing the upstream minimum height from $h_{1}=1.25$ " to $\mathrm{h}_{1}=1.15^{\prime \prime}$ improved thrust-vector angle and thrustvectoring efficiency, it resulted in a $2.2 \%$ penalty in thrust ratio. Decreasing the upstream minimum height not only decreased the pressures (thrust) along the upper wall in the recessed cavity section, but also decreased pressures (thrust) along the lower wall downstream of the injection, as shown in figure 7 . However, the overall asymmetric pressure loading increased slightly as upstream minimum height decreased, which resulted in an increase in thrust-vector angle.

\section{Effect of Cavity Length}

The effect of cavity length (L) on nozzle performance of cases with fluidic injection turned on and cavity convergence angles of $\square_{2}=20^{\circ}$ and $\square=15.46^{\circ}$, is shown in Tables 3 and 4 , respectively. Decreasing cavity length from $\mathrm{L}=1.495^{\prime \prime}$ to $\mathrm{L}=1.0^{\prime \prime}$ improved thrust-vectoring efficiency slightly for both cavity convergence angles. Additionally, thrust ratio was improved approximately $1.5 \%$ by decreasing the length of the cavity.

\section{Effect of Cavity Convergence Angle}

The effect of cavity convergence angle $\left(\square_{2}\right)$ on nozzle performance of cases with fluidic injection turned on is shown in Table 5. Increasing the 
recessed cavity convergence angle improved thrustvector angle with little thrust performance penalty. Figure 8 presents the effect of cavity convergence angle on normalized static pressure along the upper and lower walls of the nozzle. Increasing $\square_{2}$ increased static pressure on the aft portion of the nozzle upper wall; this probably accounts for the increased thrust vector angle.

\section{Addition of an Aft Deck}

The best thrust-vectoring efficiency achieved with the symmetric nozzle was case 29 , which had no aft deck, a cavity length of $\mathrm{L}=1.0 \mathrm{"}$, a cavity divergence angle of $\square_{1}=-10^{\circ}$, and a cavity convergence angle of $\mathrm{C}_{\mathrm{b}}=20^{\circ}$. Therefore, this configuration was chosen as a baseline to further investigate the effects of an aft lower deck on nozzle performance and thrust-vector angle. By adding a lower aft deck, the geometry becomes asymmetric and henceforth, the configuration has an inherent thrust-vector angle simply due to the geometry.

\section{Effect of Straight, Aft Deck Angle}

The effects of lower- and upper-wall fluidic injection on nozzle performance of a straight, lower aft deck configuration are shown in Tables 6 and 7, respectively. Adding a $\square=0^{\circ}$ straight aft deck was extremely detrimental to thrust-vector angle. Thrustvectoring efficiency with the $\square=0^{\circ}$ straight aft deck was decreased $2 \%$-injection with lower-wall injection (case 38 ) and $1.5 \%$-injection with upper-wall injection (case 39 ), compared to the symmetric baseline nozzle (case 29). This effect was expected since the aft deck would tend to turn the exhaust flow back toward the axial direction. Although the $\square=0^{\circ}$ straight aft deck would be the most clandestine configuration, an aft deck angle steeper than $\square=10^{\circ}$ would provide even more thrustvector angle than the baseline configuration with no aft deck. Increasing aft deck angle from $\square=0^{\circ}$ to $\square=25^{\circ}$ improved thrust vectoring in both directions, that is with either lower- or upper-wall fluidic injection. Thrust vectoring and thrust performance of configurations with $\square=0^{\circ}, 10^{\circ}$, and $20^{\circ}$ aft deck angles are shown in Tables 8-10, respectively.

Figures 9-11 show the Mach contours for the no fluidic injection, lower-wall fluidic injection, and upperwall fluidic injection cases with the $\square=20^{\circ}$ straight aft deck angle configuration. The sonic line, shown in black, was situated at the trailing edge of the symmetric portion of the nozzle for the non-vectoring case (figure 9 ). In the thrust vectoring mode, the sonic line shifted upstream to the new effective minimum area, that was created with the introduction of fluidic injection (figures 10-11). By injecting flow on the lower-wall at the upstream minimum area, the jet was vectored downward $\left(\square_{1}=22.6^{\circ}\right)$ and the flow remained attached to approximately $80 \%$ of the lower aft deck length. Injecting flow on the upper-wall at the upstream minimum area caused the flow to separate from the lower aft deck at about $25 \%$ of the length, while the plume was vectored in the upward direction $\left(\square_{p}=-8.1^{\circ}\right)$.

\section{Effect of Aft Deck Curvature}

Several aft deck configurations were investigated with various curvatures in an attempt to increase thrust-vector angle. The curved aft decks had larger terminal angles than the straight aft decks in hopes to achieve larger thrust-vector angles. Figure 12 shows the aft deck curvature for the tangent arc, the translated tangent arc, and the rotated tangent arc configurations that were simulated. Two additional configurations were investigated by extending the trailing edge of the tangent arc and the translated tangent arc to 4 inches, instead of terminating at 3.5 inches.

The effect of aft deck curvature on thrust-vector angle and thrust efficiency for cases with fluidic injection turned off is shown in Table 11. Adding the tangent arc aft deck to the symmetric nozzle resulted in an asymmetric configuration and a nonzero thrustvector angle $\left(\square_{p}=-12.4^{\circ}\right)$ in non-vector (no fluidic injection) mode at NPR=3.858. By rotating the tangent arc aft deck downward, as shown in figure 12, thrust-vector angle was nearly eliminated $\left(\square_{p}=0.27^{\circ}\right)$ at $\mathrm{NPR}=3.858$. Figures 13 and 14 show the Mach contours for the tangent arc and rotated tangent arc aft deck configurations in non-vector mode at $\mathrm{NPR}=3.858$, respectively. For the tangent arc aft deck configuration, the sonic line is angled from the trailing edge of the upper wall to a location approximately $24 \%$ of the length of the aft deck and the flow remains attached to $66 \%$ of the aft deck, figure 13. However, rotating the curvature downward aligns the sonic line to the end of the symmetric portion of the nozzle and the flow remains attached to $56 \%$ of the aft deck, figure 14 .

The effect of fluidic injection on thrust vectoring and thrust efficiency for the tangent arc, the translated tangent arc, the rotated tangent arc, the extended tangent arc and the extended translated tangent arc configurations are shown in Tables 12-16, respectively. The rotated tangent arc aft deck provided the best range of thrust-vector angle at an NPR=3.858. However, the tangent arc aft deck provides slightly more concealment of the core flow than the rotated tangent arc aft deck. It should be noted that these 
results will probably be different at other values of NPR.

\section{Effect of Aft Deck Blowing}

Aft deck blowing was used to investigate the ability of fluidic injection to eliminate flow separation from the aft deck in an effort to increase thrust vectoring. The Mach contours for the tangent arc, aft deck configuration with no fluidic injection (case 59) are shown in figure 13. The effect of aft deck blowing (tangent to the deck) at an axial location of $\mathrm{x}=2.8$ inches along the tangent arc, aft deck configuration (case 65) is shown in figure 15. Aft deck blowing at this location did not relieve flow separation and had little impact on thrust-vector angle, as indicated in Table 17. The flow remained attached to the wall further down the ramp and thrust-vector angle was decreased $4^{\circ}$ (compared to no blowing on the aft deck) with aft deck blowing moved to $x=3.2$ inches (case 67), as shown in figure 16. Although this effort was not investigated further, it appears that some aft deck blowing could be used to further manipulate thrustvector angle.

\section{CONCLUSIONS}

A computational investigation has been completed to assess the use of fluidic injection to control separation in a recessed cavity section of a nozzle to enhance the thrust vectoring capability of a throat shifting nozzle concept. Nozzle design variables included cavity convergence angle, cavity length, fluidic injection angle, upstream minimum height, aft deck angle and aft deck shape. The structured-grid, computational fluid dynamics code PAB3D was used to guide the design and analyze over 60 configurations. All simulations were computed with a static freestream Mach number of 0.05 , a nozzle pressure ratio of 3.858, and a fluidic injection flow rate equal to 6 percent of the primary flow rate.

The recessed cavity nozzle concept was successful at obtaining substantial thrust-vector angles without large penalties in thrust efficiency. Distinct conclusions from this work include:

1. Shifting the sonic line was not required to vector the primary flow. Control of flow separation within the recessed cavity was the key to obtaining substantial thrust-vector angles.

2. The best thrust vector efficiency was achieved:

- with the largest fluidic injection angle, that was in most opposition to the primary flow.
- with equivalent upstream and downstream minimum heights, but at the expense of thrust ratio.

- by increasing cavity convergence angle, with negligible effects on thrust efficiency.

3. Thrust efficiency was improved by shortening the cavity length, which also improved thrustvectoring efficiency slightly.

4. Adding an aft deck resulted in an asymmetric geometry and a non-zero inherent thrust-vector angle in a non-vectoring mode.

5. The $20^{\circ}$ straight aft deck achieved the best thrustvectoring efficiency of all the asymmetric configurations.

6. The rotated tangent arc deck curvature had a $0.27^{\circ}$ thrust-vector angle in the non-vector mode (no fluidic injection) and provided the best overall range of thrust-vector angle (plus and minus) at a nozzle pressure ratio of 3.858 .

7. Aft deck blowing decreased the flow separation from the aft deck and reduced the inherent thrustvector angle by $4^{\circ}$.

\section{REFERENCES}

1. Anderson, C. J.; Giuliano, V. J.; and Wing, D. J.: Investigation of Hybrid Fluidic / Mechanical Thrust Vectoring for Fixed-Exit Exhaust Nozzles. AIAA $97-$ 3148, July 1997.

2. Waithe, K. A.: An Experimental and Computational Investigation of Multiple Injection Ports in a Convergent-Divergent Nozzle for Fluidic Thrust Vectoring. Master of Science Thesis, May 2001.

3. Deere, K. A.: Computational Investigation of the Aerodynamic Effects on Fluidic Thrust Vectoring. AIAA 2000-3598, July 2000.

4. Wing, David J.; and Giuliano, V. J.: Fluidic Thrust Vectoring of an Axisymmetric Exhaust Nozzle at Static Conditions. ASMEFEDSM97-3228, June 1997.

5. Giuliano, V. J.; and Wing, D. J.: Static Investigation of a Fixed-Aperture Exhaust Nozzle Employing Fluidic Injection for Multiaxis Thrust Vector Control. AIAA 97-3149, July 1997.

6. Deere, K. A.; and Wing, D. J.: PAB3D Simulations of a Nozzle with Fluidic Injection for Yaw-ThrustVector Control. AIAA98-3254, July 1998.

7. Hunter, C. A.; and Deere, K. A.: Computational Investigation of Fluidic Counterflow Thrust Vectoring. AIAA 99-2669, June 1999.

8. Flamm, J. D.: Experimental Study of a Nozzle Using Fluidic Counterflow for Thrust Vectoring. AIAA 983255, July 1998.

9. Wing, D. J.: Static Investigation of Two Fluidic Thrust-Vectoring Concepts on a Two-Dimensional 
AIAA-2003-3803

Convergent-Divergent Nozzle. NASA TM-4574, December 1994.

10. Federspiel, J.; Bangert, L.; and Wing, D.: Fluidic Control of Nozzle Flow - Some Performance Measurements. AIAA 95-2605, July 1995.

11. Asbury, S. A.; and Capone, F. J.: Multiaxis ThrustVectoring Characteristics of a Model Representative of the F-18 HARV at AOA from $0^{\circ}$ to $70^{\circ}$. NASA TP 3531, 1995.

12. Asbury, S. A.: Internal Performance of a Fixed-Shroud Nonaxisymmetric Nozzle Equipped with an Aft-Hood Exhaust Deflector. NASA TM 97-206255, 1997.

13. Berrier, B. L.; and Mason, M.: Static Performance of an Axisymmetric Nozzle with Post-Exit Vanes for MATV. NASA TP 2800, 1988.

14. Leavitt, L. D.; Lamb, M.; and Frassinelli, Bennett: Static Investigation of a Multiaxis Thrust-Vectoring Nozzle Concept Featuring Diagonal Throat Hinge. NASA TP 3492, 1994.

15. Cler, D. L.: Internal Performance of Two Gimballed Nozzle Concepts with MATV and Reduced Observable Design. NASA TP 3464, 1994.

16. Wing, D. J.: Static Performance Investigation of a Skewed-Throat MATV Nozzle Concept. NASA TP 3411, 1994.

17. Miller, D. N.; Yagle, P. J.; and Hamstra, J. W.: Fluidic Throat Skewing for Thrust Vectoring in Fixed Geometry Nozzles. AIAA 99-0365, January 1999.

18. Yagle, P. J.; Miller, D. N.; Ginn, K. B.; and Hamstra, J. W.: Demonstration of Fluidic Throat Skewing For Thrust Vectoring In Structurally Fixed Nozzles. 2000GT-0013.

19. Abdol-Hamid, K. S.: Implementation of Algebraic Stress Models in a General 3-D Navier-Stokes Method (PAB3D). NASA CR-4702, 1995.

20. Abdol-Hamid, K. S.: Application of a Multiblock/ Multizone Code (PAB3D) for the Three-Dimensional Navier-Stokes Equations. AIAA-91-2155, June 1991.

21. van Leer, B.: Flux-Vector Splitting for the Euler Equations. ICASE Report 82-30, 1982.

22. Roe, P. L.: Characteristics Based Schemes for the Euler Equations. A Numerical Review of Fluid Mechanics, 1986, pp. 337-365.

23. Abdol-Hamid, K. S.; Lakshmanan, B.; and Carlson, J. R.: Application of Navier-Stokes Code PAB3D With $k-\square$ Turbulence Model to Attached and Separated Flows. NASA TP-3480, January 1995.

24. Balakrishnan, L.; and Abdol-Hamid, K. S.: A Comparative Study of Two Codes with an Improved Two-Equation Turbulence Model For Predicting Jet Plumes. AIAA 922604, June 1992.

25. Pao, S. P.; and Abdol-Hamid, K. S.: Numerical Simulation of Jet Aerodynamics Using the Three-Dimensional NavierStokes Code PAB3D. NASATP3596, September 1996.

26. Jones, W. P.; and Launder, B. E.: The Prediction of Laminarization With a Two-Equation Model of Turbulence. Int. Journal of Heat \& Mass Transfer, vol. 15, no. 2, February 1972, pp. 301-314.

\begin{tabular}{lllll}
\hline Case & $\square\left({ }^{\circ}\right)$ & $\square_{b}\left({ }^{\circ}\right)$ & $\square(\% / \%$-injection $)$ & $\mathrm{C}_{\mathrm{fg} . \mathrm{svs}}$ \\
\hline 25 & none & 0 & 0 & 0.976 \\
26 & 50 & 4.89 & 0.84 & 0.963 \\
24 & 90 & 10.8 & 1.71 & 0.965 \\
28 & 130 & 13.57 & 2.07 & 0.961 \\
29 & 150 & 14.67 & 2.15 & 0.957 \\
\hline
\end{tabular}

Table 1. Effect of fluidic injection angle ( $\square$ ) on nozzle performance. $\mathrm{L}=1.0^{\prime \prime}, \square_{1}=-10^{\circ}$, and $\square_{2}=20^{\circ}$.

\begin{tabular}{lllll}
\hline Case & $\mathrm{h}_{1}$ (in.) & $\mathrm{\complement}_{\mathrm{b}}\left({ }^{\circ}\right)$ & $\square(\%$ \%-injection $)$ & $\mathrm{C}_{\mathrm{fq} . \mathrm{ys}}$ \\
\hline 18 & 1.15 & 9.74 & 1.56 & 0.949 \\
19 & 1.2 & 9.55 & 1.54 & 0.961 \\
20 & 1.25 & 7.91 & 1.34 & 0.971 \\
\hline
\end{tabular}

Table 2. Effect of upstream minimum height $\left(\mathrm{h}_{1}\right)$ on nozzle performance for cases with fluidic injection turned on. $\mathrm{L}=1.495^{\prime \prime}, \square_{1}=-10^{\circ}$, and $\square_{2}=15.46^{\circ}$.

\begin{tabular}{lllll}
\hline Case & $\mathrm{L}$ (in.) & $\mathrm{\square}_{\mathrm{b}}\left({ }^{\circ}\right)$ & $\square(\% / \%$-injection) & $\mathrm{C}_{\mathrm{fo.svs}}$ \\
\hline 24 & 1.0 & 10.8 & 1.71 & 0.965 \\
21 & 1.495 & 10.7 & 1.66 & 0.95 \\
\hline
\end{tabular}

Table 3. Effect of cavity length (L) on nozzle performance for cases with fluidic injection turned on. $\square_{1}=-10^{\circ}$ and $\square_{2}=20^{\circ}$.

\begin{tabular}{lllll}
\hline Case & $\mathrm{L}$ (in.) & $\mathrm{\complement}_{\mathrm{b}}\left({ }^{\circ}\right)$ & $\square(\% / \%$-injection) & $\mathrm{C}_{\mathrm{fg.svs}}$ \\
\hline 23 & 1.0 & 10.21 & 1.62 & 0.963 \\
18 & 1.495 & 9.74 & 1.56 & 0.949 \\
\hline
\end{tabular}

Table 4. Effect of cavity length (L) on nozzle performance for cases with fluidic injection turned on. $\square_{1}=-10^{\circ}$ and $\square_{b}=15.46^{\circ}$.

\begin{tabular}{lllll}
\hline Case & $\square_{b}\left({ }^{\circ}\right)$ & $\square_{b}\left({ }^{\circ}\right)$ & $\square(\% / \%$-injection $)$ & $\mathrm{C}_{\mathrm{fg.svs}}$ \\
\hline 22 & 9.55 & 9.25 & 1.49 & 0.968 \\
23 & 15.46 & 10.21 & 1.62 & 0.963 \\
24 & 20 & 10.8 & 1.71 & 0.965 \\
\hline
\end{tabular}

Table 5. Effect of cavity convergence angle $(\square)$ on nozzle performance for cases with fluidic injection turned on. $\mathrm{L}=1.0^{\prime \prime}$ and $\square_{1}=-10^{\circ}$.

\begin{tabular}{lllll}
\hline Case & $\square\left({ }^{\circ}\right)$ & $\square_{b}\left({ }^{\circ}\right)$ & $\square(\% / \%$-injection $)$ & $\mathrm{C}_{\mathrm{fg} . \mathrm{sss}}$ \\
\hline 29 & No deck & 14.67 & 2.15 & 0.957 \\
38 & 0 & -3.66 & 0.08 & 0.959 \\
30 & 10 & 11.08 & 0.82 & 0.959 \\
31 & 17 & 20.23 & 1.45 & 0.943 \\
33 & 25 & 24.15 & 1.68 & 0.943 \\
\hline
\end{tabular}

Table 6. Effect of deck and deck angle $(\square)$ on nozzle performance. Lower-wall $6 \%$ injection, $\mathrm{L}=1.0 ", \square_{1}=$ $10^{\circ}$, and $\square_{b}=20^{\circ}$. 


\begin{tabular}{lllll}
\hline Case & $\square\left({ }^{\circ}\right)$ & $\square_{b}\left({ }^{\circ}\right)$ & $\square\left({ }^{\circ} / \%\right.$-injection $)$ & $\mathrm{C}_{\mathrm{f} \mathrm{s}, \mathrm{sv}}$ \\
\hline 29 & No deck & 14.67 & 2.15 & 0.957 \\
39 & 0 & 0.08 & 0.63 & 0.926 \\
34 & 10 & -4.84 & 1.49 & 0.906 \\
35 & 25 & -12.55 & 3.70 & 0.935 \\
\hline
\end{tabular}

Table 7. Effect of deck and deck angle ( $\square$ ) on nozzle performance. Upper-wall $6 \%$ injection, $\mathrm{L}=1.0 ", \mathrm{D}_{1}=$ $10^{\circ}$, and $\square_{\mathrm{b}}=20^{\circ}$.

\begin{tabular}{lllll}
\hline Case & $\%$ injection & $\square_{\mathrm{b}}\left({ }^{\circ}\right)$ & $\square(\%$-injection $)$ & $\mathrm{C}_{\mathrm{fg} . \mathrm{svs}}$ \\
\hline 40 & 0 & -4.26 & & 0.976 \\
38 & $7.11(\mathrm{LWI})$ & -3.66 & 0.08 & 0.959 \\
39 & $6.86(\mathrm{UWI})$ & 0.08 & 0.63 & 0.926 \\
\hline
\end{tabular}

Table 8. Effect of injection on nozzle performance of baseline configuration with a $0^{\circ}$ straight aft deck. $\mathrm{L}=1.0^{\prime \prime}, \square_{1}=-10^{\circ}$, and $\square_{2}=15.46^{\circ}$.

\begin{tabular}{lllll}
\hline Case & $\%$ injection & $\square_{0}\left({ }^{\circ}\right)$ & $\square(\%$-injection) & $\mathrm{C}_{\mathrm{f}, \mathrm{svs}}$ \\
\hline 36 & 0 & 5.34 & & 0.963 \\
30 & $6.97(\mathrm{LWI})$ & 11.08 & 0.82 & 0.959 \\
34 & $6.85(\mathrm{UWI})$ & -4.84 & 1.49 & 0.906 \\
\hline
\end{tabular}

Table 9. Effect of injection on nozzle performance of baseline configuration with a $10^{\circ}$ straight aft deck. $\mathrm{L}=1.0^{\prime \prime}, \square_{1}=-10^{\circ}$, and $\square_{b}=15.46^{\circ}$.

\begin{tabular}{lllll}
\hline Case & $\%$ injection & $\square_{b}\left({ }^{\circ}\right)$ & $\square(\% / \%$-injection $)$ & $\mathrm{C}_{\mathrm{fg}, \text { vs }}$ \\
\hline 47 & 0 & 11.24 & & 0.926 \\
48 & $6.44(\mathrm{LWI})$ & 22.6 & 1.76 & 0.95 \\
49 & $6.45(\mathrm{UWI})$ & -8.13 & 3.0 & 0.902 \\
\hline
\end{tabular}

Table 10. Effect of injection on nozzle performance of baseline configuration with a $20^{\circ}$ straight aft deck. $\mathrm{L}=1.0^{\prime \prime}, \square_{1}=-10^{\circ}$, and $\square_{2}=15.46^{\circ}$.

\begin{tabular}{lcrl}
\hline Case & $\%$ injection & \multicolumn{1}{c}{$\square_{b}\left({ }^{\circ}\right)$} & $\mathrm{C}_{\mathrm{fg} . \mathrm{sv}}$ \\
\hline 50 (TA) & 0 & -12.42 & 0.962 \\
53 (TTA) & 0 & -5.22 & 0.969 \\
56 (RTA) & 0 & 0.27 & 0.950 \\
59 (ETA) & 0 & -11.94 & 0.957 \\
62 (ETTA) & 0 & -4.68 & 0.964 \\
\hline
\end{tabular}

Table 11. Effect of aft deck curvature on thrust-vector angle and thrust efficiency for cases with fluidic injection turned off.

\begin{tabular}{|c|c|c|c|c|}
\hline Case & $\%$ injection & $\square_{b}\left({ }^{\circ}\right)$ & $\square(\% / \%$-injection $)$ & $\mathrm{C}_{\mathrm{fg}, \mathrm{sys}}$ \\
\hline 50 & 0 & -12.42 & & 0.962 \\
\hline 51 & 7.17 (LWI) & -2.4 & 1.4 & 0.935 \\
\hline 52 & 6.44 (UWI) & -13.53 & 0.17 & 0.925 \\
\hline
\end{tabular}

Table 12. Effect of injection on nozzle performance of baseline configuration with a tangent arc, aft deck.

\begin{tabular}{llrcc}
\hline Case & $\%$ injection & $\square_{0}\left({ }^{\circ}\right)$ & $\square(\%$-injection $)$ & $\mathrm{C}_{\mathrm{fq}, \mathrm{svs}}$ \\
\hline 53 & 0 & -5.22 & & 0.969 \\
54 & $6.67(\mathrm{LWI})$ & 5.55 & 1.62 & 0.947 \\
55 & $6.41(\mathrm{UWI})$ & -5.47 & 0.04 & 0.932 \\
\hline
\end{tabular}

Table 13. Effect of injection on nozzle performance of baseline configuration with a translated tangent arc, aft deck.

\begin{tabular}{llrcc}
\hline Case & $\%$ injection & $\square_{b}\left({ }^{\circ}\right)$ & $\square(\% / \%$-injection $)$ & $\mathrm{C}_{\mathrm{fg} . \mathrm{svs}}$ \\
\hline 56 & 0 & 0.27 & & 0.950 \\
57 & $6.64(\mathrm{LWI})$ & 10.96 & 1.61 & 0.936 \\
58 & $6.42(\mathrm{UWI})$ & -8.27 & 1.33 & 0.922 \\
\hline
\end{tabular}

Table 14. Effect of injection on nozzle performance of baseline configuration with a rotated tangent arc, aft deck.

\begin{tabular}{llrcc}
\hline Case & $\%$ injection & $\mathrm{\square}_{0}\left({ }^{\circ}\right)$ & $\square(\%$-injection $)$ & $\mathrm{C}_{\mathrm{f} \text {. svs }}$ \\
\hline 59 & 0 & -11.94 & & 0.957 \\
60 & $7.24(\mathrm{LWI})$ & -1.02 & 1.51 & 0.924 \\
61 & $6.43(\mathrm{UWI})$ & -13.44 & 0.23 & 0.919 \\
\hline
\end{tabular}

Table 15. Effect of injection on nozzle performance of baseline configuration with an extended tangent arc, aft deck.

\begin{tabular}{llrcc}
\hline Case & $\%$ injection & $\square_{b}\left({ }^{\circ}\right)$ & $\square(\%$ (\%-injection $)$ & $\mathrm{C}_{\mathrm{f}, \mathrm{svs}}$ \\
\hline 62 & 0 & -4.68 & & 0.964 \\
63 & $6.64(\mathrm{LWI})$ & 5.06 & 1.47 & 0.944 \\
64 & $6.43(\mathrm{UWI})$ & -6.34 & 0.26 & 0.932 \\
\hline
\end{tabular}

Table 16. Effect of injection on nozzle performance of baseline configuration with an extended, translated tangent arc, aft deck.

\begin{tabular}{llrcc}
\hline Case & $\begin{array}{c}\% \text { of } \\
\text { deck injection }\end{array}$ & $\square_{\mathrm{p}}\left({ }^{\circ}\right)$ & $\square(\% / \%$-injection $)$ & $\mathrm{C}_{\mathrm{fg}, \mathrm{sys}}$ \\
\hline 59 & 0 & -11.94 & & 0.957 \\
65 & $6 \%$ at 2.8 in. & -11.82 & 0.1 & 0.958 \\
67 & $6 \%$ at 3.2 in. & -7.98 & 0.7 & 0.935 \\
\hline
\end{tabular}

Table 17. Effect of deck injection with the tangent arc aft deck configuration. 


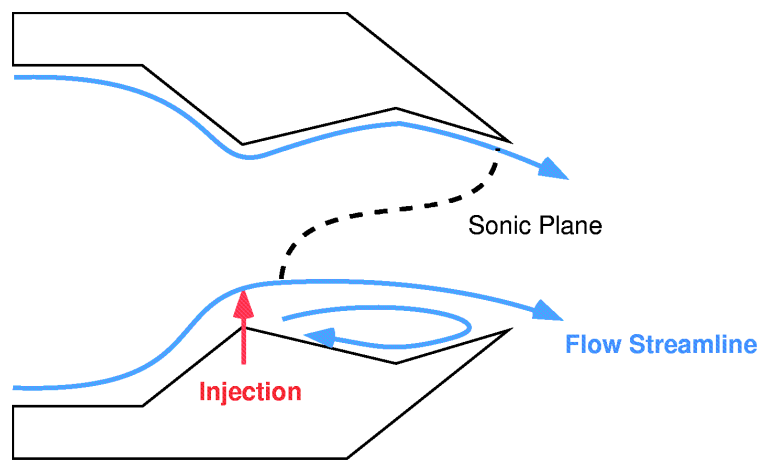

Figure 1. A sketch of the recessed cavity nozzle concept. Fluidic injection located at the upstream minimum area.

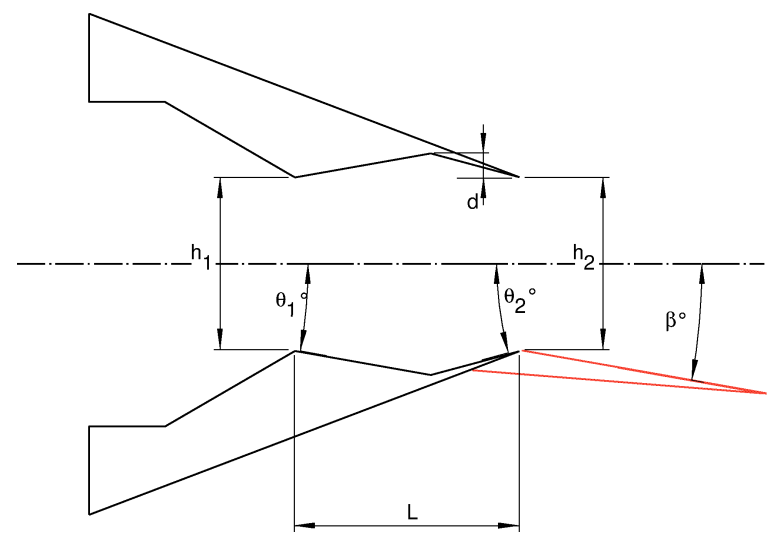

Figure 2. Sketch of the design variables for the recessed cavity nozzle.

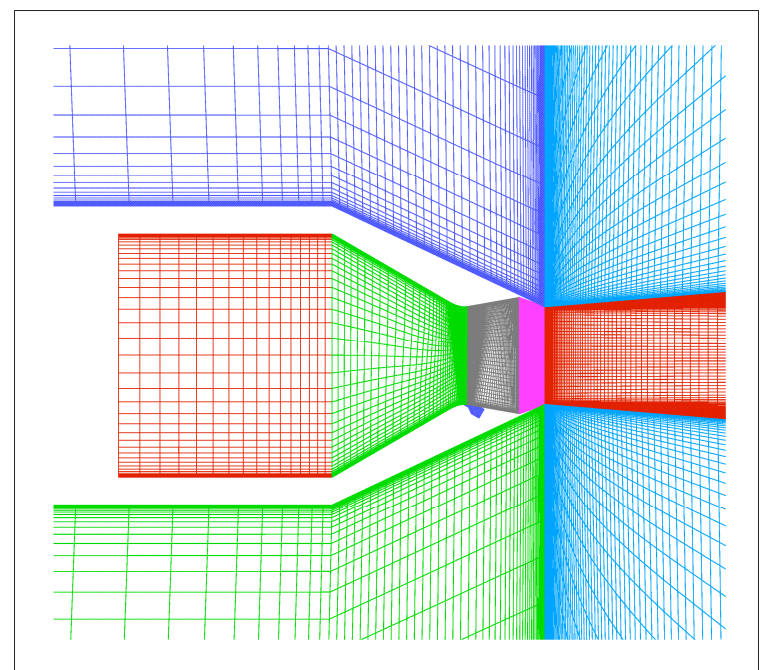

Figure 3. The internal blocks representing the symmetric nozzle configuration with a recessed cavity and a lower-wall fluidic injection plenum.

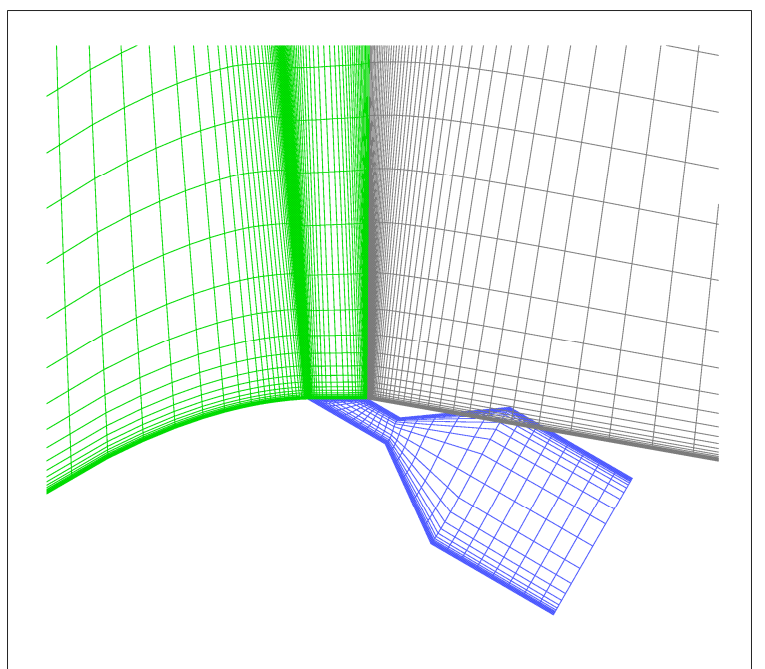

Figure 4. The injection plenum has one-to-one grid matching with the primary nozzle grid.

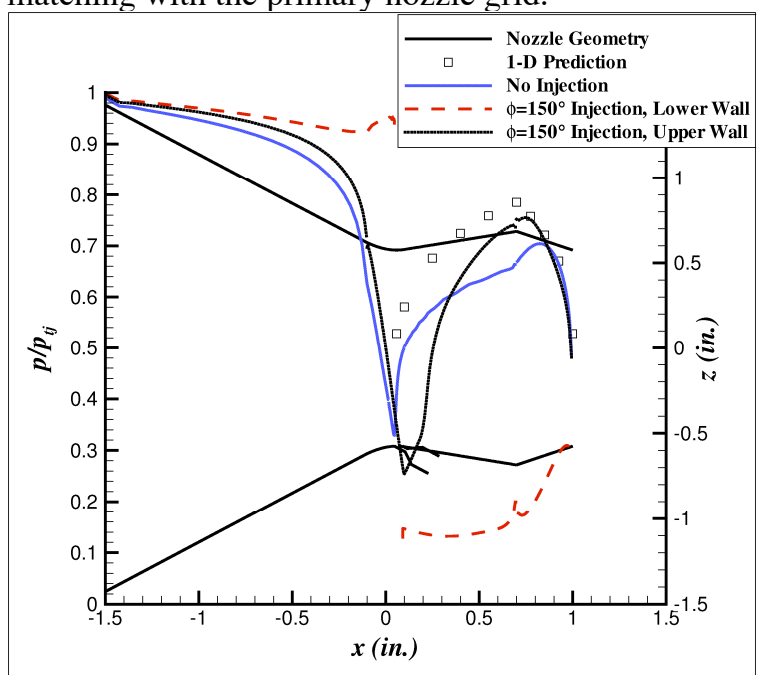

Figure 5. Nozzle pressure ratio distributions for the symmetric baseline nozzle. Data includes the no fluidic injection case, the $\square=150^{\circ}$ injection case, and the 1-D predictions from isentropic stream-tube-area relations.

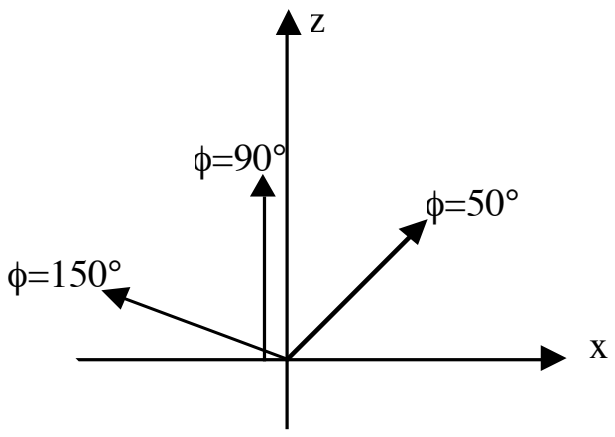

Figure 6. Diagram of injection angle in the twodimensional, $\mathrm{x}-\mathrm{z}$ plane. 


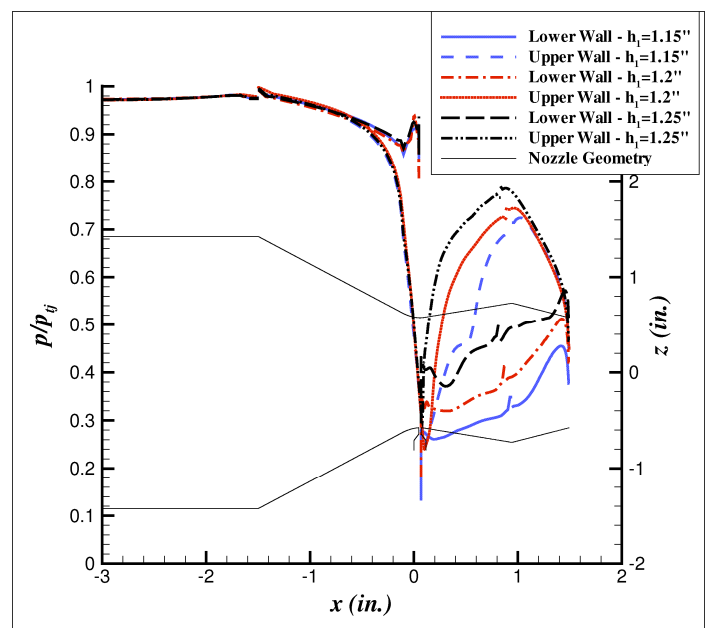

Figure 7. Effect of upstream minimum height on normalized static pressure with lower-wall injection, $\mathrm{L}=1.495^{\prime \prime}, \square_{2}=15.46^{\circ}$, and $\square_{1}=-10^{\circ}$.

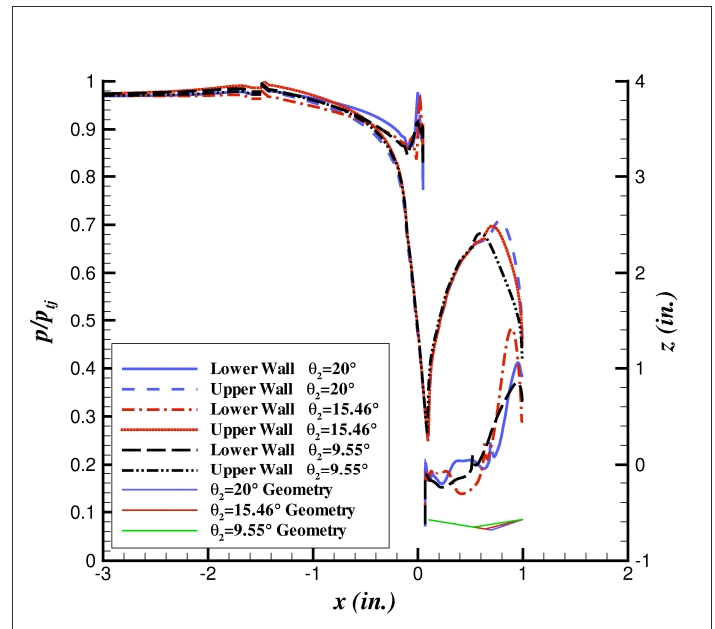

Figure 8. Effect of cavity convergence angle on normalized static pressure with lower-wall injection and $\mathrm{L}=1.0^{\prime \prime}$.

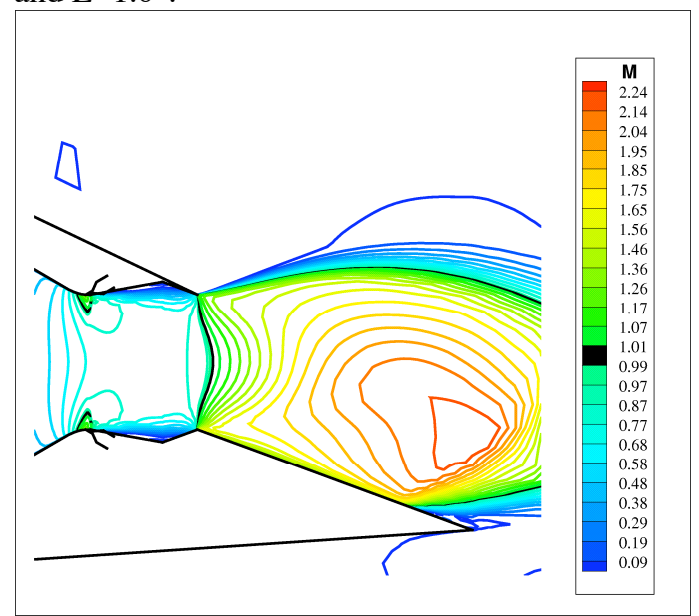

Figure 9. Mach contours for the $20^{\circ}$ aft deck simulation with no fluidic injection, $\square_{p}=11.2^{\circ}$.



Figure 10. Mach contours for the $20^{\circ}$ aft deck simulation with fluidic injection at the lower wall upstream minimum area, $\square_{0}=22.6^{\circ}$.

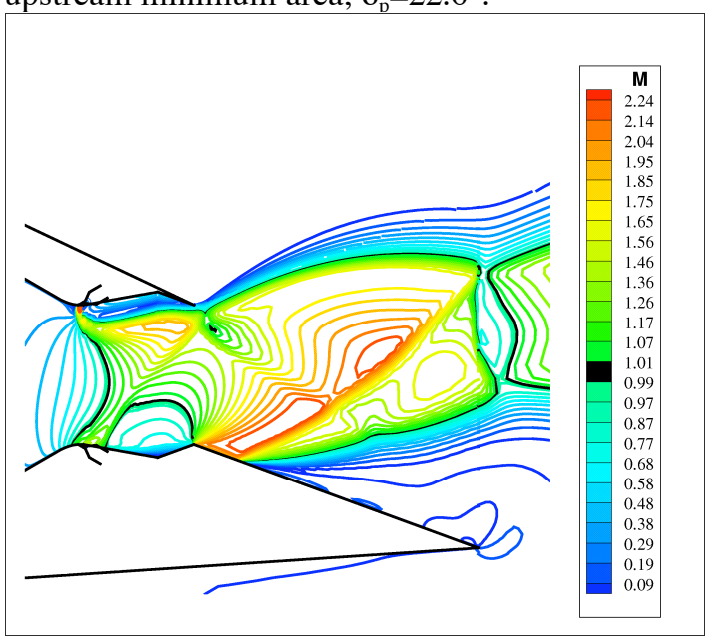

Figure 11. Mach contours for the $20^{\circ}$ aft deck simulation with fluidic injection at the upper wall upstream minimum area, $\Pi_{p}=-8.1^{\circ}$.

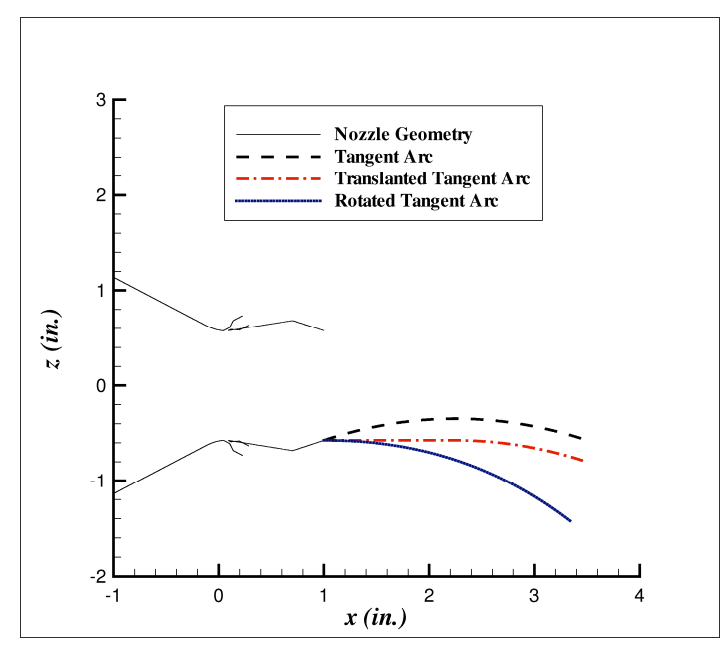

Figure 12. Comparison of aft deck curvature. 




Figure 13. Mach contours for the tangent arc aft deck simulation in non-vector mode, $\square_{p}=-11.94^{\circ}$.



Figure 14. Mach contours for the rotated tangent arc aft deck simulation in non-vector mode, $\square_{p}=0.27^{\circ}$.

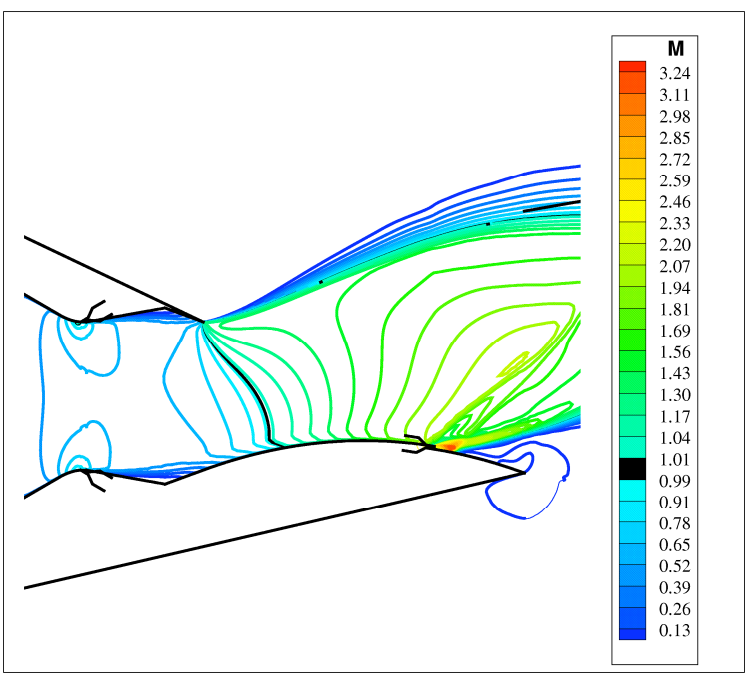

Figure 15. Mach contours for the tangent arc aft deck configuration with deck fluidic injection at $\mathrm{x}=2.8$ inches, $\square_{p}=-11.82^{\circ}$.

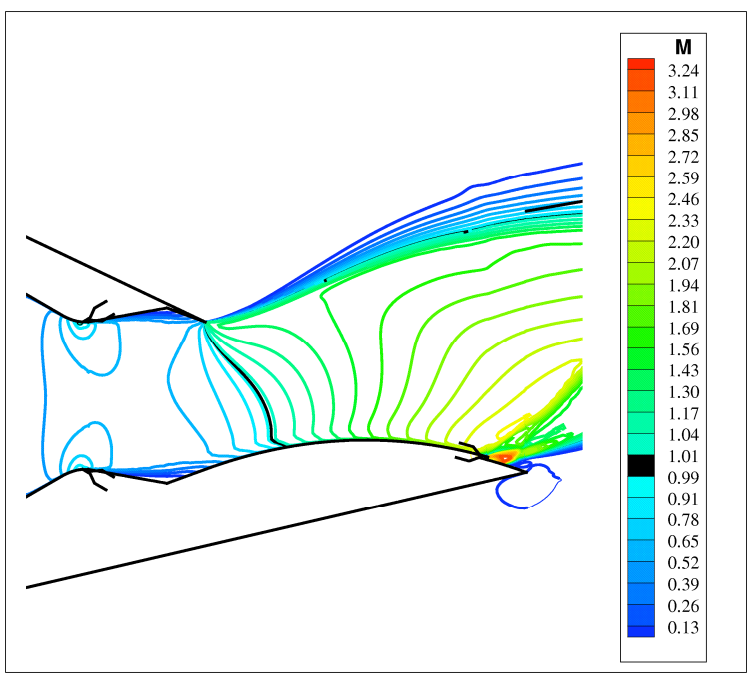

Figure 16. Mach contours for the tangent arc aft deck configuration with deck fluidic injection at $\mathrm{x}=3.2$ inches, $\complement_{p}=-7.98^{\circ}$. 